\title{
Population Structure and Resistance to Mefenoxam of Phytophthora capsici in New York State
}

A. R. Dunn, Department of Plant Pathology and Plant-Microbe Biology, Cornell University, Geneva, NY 14456; M. G. Milgroom, Department of Plant Pathology and Plant-Microbe Biology, Cornell University, Ithaca, NY 14853; J. C. Meitz and A. McLeod, Department of Plant Pathology, University of Stellenbosch, Stellenbosch, Private Bag X1, Matieland 7602, South Africa; W. E. Fry, Department of Plant Pathology and Plant-Microbe Biology, Cornell University, Ithaca, NY 14853; M. T. McGrath, Department of Plant Pathology and Plant-Microbe Biology, Cornell University, Riverhead, NY 11901; and H. R. Dillard and C. D. Smart, Department of Plant Pathology and PlantMicrobe Biology, Cornell University, Geneva, NY 14456

\begin{abstract}
Dunn, A. R., Milgroom, M. G., Meitz, J. C., McLeod, A., Fry, W. E., McGrath, M. T., Dillard, H. R., and Smart, C. D. 2010. Population structure and resistance to mefenoxam of Phytophthora capsici in New York State. Plant Dis. 94:1461-1468.

In 2006, 2007, and 2008, we sampled 257 isolates of Phytophthora capsici from vegetables at 22 sites in four regions of New York, to determine variation in mefenoxam resistance and population genetic structure. Isolates were assayed for mefenoxam resistance and genotyped for mating type and five microsatellite loci. We found mefenoxam-resistant isolates at a high frequency in the Capital District and Long Island, but none were found in western New York or central New York. Both A1 and A2 mating types were found at 12 of the 22 sites, and we detected 126 distinct multilocus genotypes, only nine of which were found at more than one site. Significant differentiation $\left(\mathrm{F}_{\mathrm{ST}}\right)$ was found in more than $98 \%$ of the pairwise comparisons between sites; approximately 24 and $16 \%$ of the variation in the population was attributed to differences among regions and sites, respectively. These results indicate that $P$. capsici in New York is highly diverse, but gene flow among regions and fields is restricted. Therefore, each field needs to be considered an independent population, and efforts to prevent movement of inoculum among fields need to be further emphasized to prevent the spread of this pathogen.
\end{abstract}

Studies of population structure in plant pathogens have revealed a variety of patterns from randomly mating to clonal, and from highly subdivided to single global populations $(1,14,34)$. Within the same species, it is not uncommon to find a variety of patterns depending on geographic location, agricultural practices, or history of introductions $(12,30)$. Because of this, it is not always possible to make inferences about population structure in one location based on findings from another.

The focus of this study is the heterothallic oomycete Phytophthora capsici, which causes Phytophthora blight on many vegetable hosts (20), resulting in devastating crop losses around the world (8). The genetic structure of $P$. capsici populations varies considerably from one location to another $(21,25-27,32)$. At one extreme is a

Corresponding author: Christine Smart E-mail: cds14@cornell.edu

* The $\boldsymbol{e}$-Xtra logo stands for "electronic extra" and indicates that a supplemental table is available online.

Accepted for publication 18 August 2010.

doi:10.1094/PDIS-03-10-0221

(c) 2010 The American Phytopathological Society clonal population that appears to be widespread across a large area of coastal Peru, where only A2 isolates were sampled over 3 years, nearly all individuals had the same amplified fragment length polymorphism (AFLP) genotype, and heterozygosity was fixed for single nucleotide polymorphisms (SNPs) at six loci (21). At the other extreme are sexual, highly subdivided populations in Michigan with A1 and A2 mating types present in the same fields, often at 1:1 ratios, high genotypic diversity, no multilocus genotypes persisting from one year to the next, and high levels of genetic differentiation between populations in different fields (25-27). Additionally, resistance to the phenylamide fungicide mefenoxam has been documented many times in $P$. capsici $(20,37)$, but the frequency of resistance varies among populations $(7,43)$. Variation in both population structure and mefenoxam resistance makes it difficult to predict a priori the specific characteristics of any given population of $P$. capsici, adding additional uncertainty to decisions concerning disease management.

Genetic structure can be viewed as a combination of the patterns of genotypic variation within a population and the genetic differentiation among populations, e.g., among fields or geographic regions
(33). Within a population, reproductive biology has a substantial effect on genetic structure $(1,34)$. Like many oomycetes, $P$. capsici reproduces both sexually and asexually. When both $\mathrm{A} 1$ and $\mathrm{A} 2$ mating types are present, sexual reproduction occurs and oospores are produced (37). In cold climates, oospores are the only inoculum that can survive the winter $(6,27)$, while sporangia and zoospores are produced asexually and contribute significantly to secondary disease cycles during a growing season (20). Therefore, genotypic diversity can be maintained by sexual reproduction, while at the same time asexual reproduction can result in the spread of clones. In contrast to within population structure, differentiation among populations is a function of restricted gene flow. In $P$. capsici, dispersal of propagules occurs naturally by splashing water, windblown rain, or in surface water (37) and therefore is relatively short distance, within fields or between nearby fields. Because P. capsici is a soilborne pathogen, and wind does not appear to be important in long-distance spread (18), humanmediated movement of infected fruits or infested soil, e.g., on farm equipment, is the most likely means of long-distance dispersal (20).

In populations of $P$. capsici in a cold climate such as that in New York State, we would predict that annual sexual reproduction is necessary for overwintering and persistence between seasons. Furthermore, given the widespread disease outbreaks we have observed within New York vegetable fields, especially following heavy rain events, we would also predict that $P$. capsici spreads clonally within fields. This combination of sexual and asexual reproduction has been inferred in Michigan populations of $P$. capsici (26), where the climate is similar to that of New York. A survey of two fields in New York (one on Long Island and one in the Capital District) reported both $\mathrm{A} 1$ and $\mathrm{A} 2$ mating types of $P$. capsici and resistance to mefenoxam, as well as high proportions of isolates with unique AFLP genotypes (20). Because population structure is known to vary considerably within $P$. capsici and has 
important implications to disease management $(12,14,31,33,34)$, a larger survey of $P$. capsici in New York is essential to gain an understanding of the specific populations affecting New York and to provide

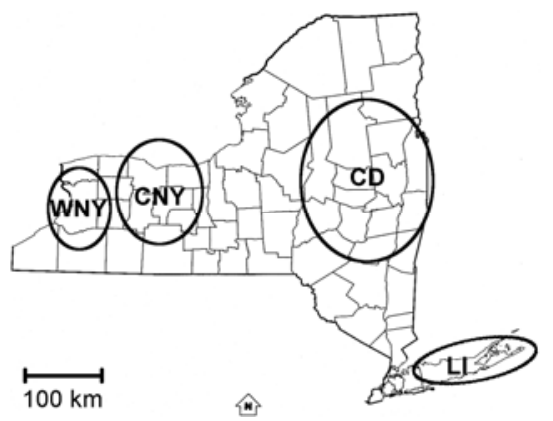

Fig. 1. Phytophthora capsici isolates were sampled in 2006, 2007, and 2008 from western New York (WNY), central New York (CNY), the Capital District (CD), and Long Island (LI). appropriate management recommendations to New York growers.

The specific objectives of this study were to determine: (i) the extent of mefenoxam resistance in $P$. capsici in New York; (ii) polymorphism for mating types and the genetic structure within populations of $P$. capsici; and (iii) whether populations of $P$. capsici are genetically differentiated among fields and regions in New York, suggesting restricted gene flow.

\section{MATERIALS AND METHODS}

Collection of symptomatic plants. In 2006, 2007, and 2008, plants showing characteristic symptoms of Phytophthora blight were collected from four vegetableproduction regions of New York. Of the 22 sites sampled, three were in western New York (Erie County), three in central New York (Monroe and Ontario counties), four in the Capital District (Herkimer, Schenectady, and Rensselaer counties), and 12 on Long Island (Suffolk County) (Fig. 1, Table 1). Each site was either a single field or a few fields in close proximity to each other. No site was sampled in more than one year. At site WNY-2, the relative locations in the field from which symptomatic plants were collected was noted (Fig. 2). At all other sites, plants were collected based on the distribution of symptomatic plants, and the relative locations of the plants within a field were not recorded. Different numbers of plants were collected from each site.

Isolation and confirmation of $\boldsymbol{P}$. capsici. Small pieces of symptomatic plant tissue were surface-disinfested and plated on PARP (39) or PARPH (35). Plates were incubated at room temperature until colonies began to grow from the tissue, at which point edges of these colonies were transferred to new PARP or PARPH plates, and then to $15 \%$ unclarified V8 agar (UCV8) (25). Isolates were identified as

Table 1. Mating type, genotypic diversity, and mefenoxam resistance of Phytophthora capsici in New York in 2006 to $2008^{\mathrm{a}}$

\begin{tabular}{|c|c|c|c|c|c|c|c|c|c|c|c|c|c|c|c|c|}
\hline \multirow[b]{2}{*}{ Site } & \multirow[b]{2}{*}{ Crop $^{c}$} & \multirow[b]{2}{*}{ Town } & \multirow[b]{2}{*}{ County } & \multirow[b]{2}{*}{ Date $^{d}$} & \multirow[b]{2}{*}{$\mathbf{N}^{\mathrm{e}}$} & \multicolumn{4}{|c|}{ Mating type } & \multicolumn{3}{|c|}{ Site-specific } & \multicolumn{4}{|c|}{ Mef. sensitivity ${ }^{b}$} \\
\hline & & & & & & A1 & A2 & $\chi^{2 \mathrm{f}}$ & $P$ & MLGsg & MLGs $^{h}$ & $D^{\prime i}$ & $\mathbf{S}$ & $\mathbf{I}$ & $\mathbf{R}$ & $\%^{\mathrm{j}}$ \\
\hline WNY-1 & Pepper & Eden & Erie & $8 / 14 / 06$ & 1 & 1 & 0 & & & 1 & 0 & & 1 & 0 & 0 & 0 \\
\hline WNY-2 & S. squash & Eden & Erie & $\begin{array}{c}6 / 19 / 07 \\
6 / 26 / 07\end{array}$ & 36 & 8 & 28 & 11.11 & 0.001 & 13 & 11 & 0.59 & 36 & 0 & 0 & 0 \\
\hline WNY-3 & Various & Eden & Erie & $\begin{array}{c}\text { Jun to } \\
\text { Aug '08 }\end{array}$ & 12 & 8 & 4 & 1.33 & $\mathrm{NS}^{\mathrm{k}}$ & 11 & 9 & 1.00 & 12 & 0 & 0 & 0 \\
\hline All WNY & & & & & 49 & 17 & 32 & & & 22 & & & 49 & $\mathbf{0}$ & $\mathbf{0}$ & $\mathbf{0}$ \\
\hline CNY-1 & Pepper & Palmyra & Monroe & $9 / 12 / 06$ & 1 & 1 & 0 & & & 1 & 0 & & 1 & 0 & 0 & 0 \\
\hline CNY-2 & W. squash & Seneca & Ontario & $9 / 18 / 06$ & 13 & 0 & 13 & 13.00 & 0.001 & 5 & 5 & 0.49 & 13 & 0 & 0 & 0 \\
\hline CNY-3 & Pumpkin & Seneca & Ontario & $7 / 31 / 07$ & 2 & 2 & 0 & & & 2 & 2 & & 2 & 0 & 0 & 0 \\
\hline All CNY & & & & & 16 & 3 & 13 & & & 8 & & & 16 & $\mathbf{0}$ & $\mathbf{0}$ & 0 \\
\hline CD-1 & Zucchini & Herkimer & Herkimer & $7 / 24 / 07$ & 13 & 6 & 7 & 1.00 & NS & 13 & 13 & 1.00 & 2 & 0 & 11 & 0.85 \\
\hline CD-2 & Various & Troy & Rensselaer & $9 / 25 / 07$ & 16 & 7 & 9 & 0.25 & NS & 7 & 5 & 0.64 & 5 & 0 & 11 & 0.69 \\
\hline CD-3 & Various & Rotterdam & Schenectady & $9 / 25 / 07$ & 6 & 4 & 2 & & & 5 & 5 & & 0 & 0 & 6 & 1.00 \\
\hline CD-4 & Pumpkin & Scotia & Schenectady & $9 / 25 / 07$ & 23 & 9 & 14 & 1.09 & NS & 19 & 16 & 0.68 & 13 & 0 & 10 & 0.43 \\
\hline All CD & & & & & 58 & 26 & 32 & & & 43 & & & 20 & 0 & 38 & 0.66 \\
\hline LI-1 & Pepper & Riverhead & Suffolk & $8 / 28 / 07$ & 11 & 7 & 4 & 0.82 & NS & 11 & 10 & 0.46 & 11 & 0 & 0 & 0 \\
\hline LI-2 & Pumpkin & Riverhead & Suffolk & 9/4/07 & 3 & 3 & 0 & & & 2 & 2 & & 1 & 0 & 2 & 0.67 \\
\hline LI-3 & Pumpkin & Riverhead & Suffolk & 9/4/07 & 4 & 4 & 0 & & & 4 & 4 & & 0 & 0 & 4 & 1.00 \\
\hline LI-4 & Pumpkin & Riverhead & Suffolk & $8 / 30 / 07$ & 7 & 6 & 1 & & & 7 & 7 & & 7 & 0 & 0 & 0 \\
\hline LI-5 & Pumpkin & Riverhead & Suffolk & 9/4/07 & 9 & 9 & 0 & & & 4 & 4 & & 9 & 0 & 0 & 0 \\
\hline LI-6 & Pumpkin & Riverhead & Suffolk & $11 / 1 / 07$ & 8 & 2 & 6 & & & 6 & 6 & & 0 & 0 & 8 & 1.00 \\
\hline LI-7 & Pumpkin & Riverhead & Suffolk & $11 / 1 / 07$ & 7 & 7 & 0 & & & 1 & 1 & & 7 & 0 & 0 & 0 \\
\hline LI-8 & Unknown & Riverhead & Suffolk & $8 / 30 / 07$ & 6 & 4 & 2 & & & 4 & 2 & & 4 & 1 & 1 & 0.17 \\
\hline LI-9 & Pumpkin & Riverhead & Suffolk & $\begin{array}{c}\text { 8/30/07 } \\
11 / 1 / 07\end{array}$ & 11 & 0 & 11 & 11.00 & 0.001 & 6 & 4 & 0.35 & 11 & 0 & 0 & 0 \\
\hline LI-10 & Pepper & Riverhead & Suffolk & $8 / 30 / 07$ & 12 & 12 & 0 & 12.00 & 0.01 & 3 & 3 & 0.26 & 11 & 0 & 1 & 0.08 \\
\hline LI-11 & Cucurbit & Riverhead & Suffolk & $8 / 20 / 07$ & 12 & 5 & 7 & 0.33 & NS & 7 & 7 & 0.39 & 12 & 0 & 0 & 0 \\
\hline LI-12 & Pumpkin & Riverhead & Suffolk & $11 / 1 / 07$ & 44 & 20 & 24 & 0.36 & NS & 5 & 5 & 0.34 & 27 & 1 & 16 & 0.36 \\
\hline All LI & & & & & 134 & 79 & 55 & & & 58 & & & 100 & 2 & 32 & 0.25 \\
\hline All NY & & & & & 257 & 125 & 132 & & & 126 & & & 185 & 2 & 70 & 0.28 \\
\hline
\end{tabular}

a Sites are grouped by region: WNY = western New York, CNY = central New York, CD = Capital District (near Albany, NY), and LI = Long Island. Only one isolate of each multilocus genotype from a single plant was included in the analysis.

${ }^{\mathrm{b}}$ Mefenoxam resistance: $\mathrm{S}=$ sensitive, $\mathrm{I}=$ intermediate resistance, $\mathrm{R}=$ resistant.

${ }^{\mathrm{c}}$ Crop from which Phytophthora capsici was isolated; S. squash $=$ summer squash, W. $\mathrm{squash}=$ winter squash.

d Sampling date for each site.

e Number of isolates sampled from each site.

${ }^{\mathrm{f}}$ Chi-square statistic (1 df) testing whether A1 and A2 isolates found at each site were in a 1:1 ratio. Chi-square tests were only performed on sites from which 10 or more isolates were sampled.

${ }^{\mathrm{g}}$ Number of multilocus genotypes (MLGs) identified at each site by mating type and alleles at five microsatellite loci.

${ }^{\mathrm{h}}$ Number of MLGs found only at a single site.

${ }^{i}$ Diversity at each site estimated with the normalized Shannon index (30). $D^{\prime}=D / \ln N$, where $N=$ number of isolates sampled at each site and $D=-\Sigma p_{i} \ln p_{i}$ (the Shannon index), where $p_{i}$ is the frequency of the $i$ th MLG. $D^{\prime}$ is only reported for sites from which at least 10 isolates were sampled, and isolates with missing data at one or more loci were excluded.

${ }^{j}$ Percentage of isolates either intermediately or fully resistant to mefenoxam.

${ }^{\mathrm{k}} \mathrm{NS}$, not significant; $P>0.05$. 
$P$. capsici by production of ovoid, papillate sporangia on long pedicels (29) when grown on UCV8 agar and exposed to light, and confirmed through species-specific polymerase chain reaction (PCR; described below). Single zoospore isolates were obtained as previously described (24), and all subsequent analyses were done with these isolates. We obtained between one and five isolates per infected plant, but only one isolate per genotype per plant was used for the analysis (see below). Cultures were maintained on UCV8, PARP, or potato dextrose agar (PDA; 39 g/liter, Becton, Dickinson and Company) and transferred every 1 to 2 months until stored. To store isolates, plugs taken from the expanding edge of a culture were transferred to sterile distilled water and maintained in the dark at room temperature (39).

Mating type and mefenoxam resistance. To determine the mating type of each isolate, a 5- to 10-mm-diameter plug taken from a 1- to 3-week-old culture was transferred to the center of a UCV8 plate, approximately $3 \mathrm{~cm}$ away from two plugs of a $P$. capsici isolate of known A1 mating type (ATCC no. MYA-2338). This procedure was repeated with a known A2 isolate of $P$. capsici (ATCC no. MYA-2290), and both plates were incubated in the dark for at least a week before being inspected under a light microscope for the presence of oospores. Isolates which formed oospores with the A1 mating type standard, but not with the A2 mating type standard were determined to be mating type A2, and vice versa (42). Plates containing plugs from both the A1 and A2 standard strains were included as positive controls.

An in vitro test was used to determine whether isolates were sensitive to mefenoxam. A 10-mm-diameter plug was cut from the edge of a 1- to 3-week-old culture of each isolate using a sterile cork borer. Plugs were transferred to the center of 100-mm-wide UCV8 plates amended with no mefenoxam, $5 \mu \mathrm{g} / \mathrm{ml}$ mefenoxam, or
$100 \mu \mathrm{g} / \mathrm{ml}$ mefenoxam (16) in the form of Ridomil Gold EC (Syngenta Crop Protection) to give the appropriate concentration of active ingredient. Plates were incubated in the dark for 3 to 7 days, until mycelia on the $0 \mu \mathrm{g} / \mathrm{ml}$ mefenoxam control had covered at least half of the plate. The diameter of each colony was measured at its widest point, and the diameter of the plug was subtracted from the diameter of each colony before calculating colony growth on mefenoxam-amended media as a percentage of the no-mefenoxam control. P. capsici isolates are frequently classified into discrete mefenoxam sensitivity phenotypes $(11,24)$, as are isolates of $P$. infestans $(16,28)$. An isolate was scored as sensitive if growth on $5 \mu \mathrm{g} / \mathrm{ml}$ mefenoxam-amended UCV8 was less than $40 \%$ of growth on the unamended UCV8; intermediately resistant if growth on $5 \mu \mathrm{g} / \mathrm{ml}$ mefenoxamamended UCV8 was greater than $40 \%$ of growth on the unamended UCV8, but growth on $100 \mu \mathrm{g} / \mathrm{ml}$ mefenoxam-amended UCV8 was less than $40 \%$ of growth on the unamended UCV8; or resistant if growth on both 5 and $100 \mu \mathrm{g} / \mathrm{ml}$ mefenoxamamended UCV8 was more than $40 \%$ of growth on the unamended UCV8 (41). All mefenoxam sensitivity tests were conducted at least twice.

Harvesting mycelia and extracting DNA. To produce mycelia from which DNA could be extracted, each isolate was grown for 1 to 3 weeks on PARP before three to four plugs (approximately $1 \mathrm{~cm}$ in diameter) were transferred to approximately $12 \mathrm{ml}$ of sterile potato dextrose broth (24 g/liter, MP Biomedicals) in $15 \times$ $100 \mathrm{~mm}$ petri dishes (Fisher Scientific). Plates were sealed with Parafilm and incubated in the dark until mycelia covered the surface of the broth. Mycelia were harvested by vacuum filtration, separated from agar plugs, and stored at $-20^{\circ} \mathrm{C}$ until DNA was extracted.

DNA was extracted using the Qiagen DNeasy Plant Mini kit or the MoBio Ul-
traClean Soil DNA kit following the manufacturers' instructions, with slight modifications to each protocol as follows. To disrupt the tissue in the first step of the Qiagen protocol, 40 to $80 \mathrm{mg}$ of thawed mycelia were placed in a round-bottom 2 $\mathrm{ml}$ microcentrifuge tube with a sterile ball bearing and shaken in a Qiagen TissueLyser at 30 cycles per second for $1 \mathrm{~min}$ and $30 \mathrm{~s}$. The process was repeated if the tissue was not completely ground. In the final step of the kit protocol, the incubation with Buffer $\mathrm{AE}$ was extended to $15 \mathrm{~min}$ and Buffer AE was added in 2 aliquots of $50 \mu \mathrm{l}$ each (with centrifugation following each incubation) to improve yield. With the MoBio kit, 30 to $70 \mathrm{mg}$ of thawed mycelia was used for extraction and the spin filter was incubated for $15 \mathrm{~min}$ at room temperature with Solution S5 before the final elution of DNA by centrifugation.

Confirmation of isolates as $P$. capsici using species-specific primers. Extracted DNA was amplified with $P$. capsicispecific primers (PC-3, 5'-GTGTTGTCC TTCGGGTCGACTG-3' and PC-6R, 5'GGAAAAGCATTCAATAAGCGCCTG) designed from previously described species-specific oligonucleotides (46). Each $25-\mu \mathrm{l}$ reaction contained $2.5 \mu \mathrm{l}$ of genomic DNA (25 ng), $0.2 \mu \mathrm{M}$ forward and reverse primers, $0.2 \mathrm{mM}$ total dNTPs, $1 \times$ ThermoPol reaction buffer with $2 \mathrm{mM} \mathrm{MgSO}$, and $0.5 \mathrm{U} \mathrm{Taq}$ DNA polymerase (New England Biolabs). The reaction took place in either an Eppendorf Mastercycler gradient (Eppendorf) or a PTC-100 Thermo Cycler (MJ Research) PCR machine with an initial incubation of $5 \mathrm{~min}$ at $94^{\circ} \mathrm{C}$, followed by 35 cycles of $94^{\circ} \mathrm{C}$ for $45 \mathrm{~s}$, $62^{\circ} \mathrm{C}$ for $45 \mathrm{~s}$, and $72^{\circ} \mathrm{C}$ for $45 \mathrm{~s}$, and a final incubation step at $72^{\circ} \mathrm{C}$ for $10 \mathrm{~min}$. The expected product was 219 base pairs in length, and products were visualized on a $1 \%$ agarose gel. Negative controls containing no genomic DNA were run with all reactions to check for contaminated reagents, and DNA from known

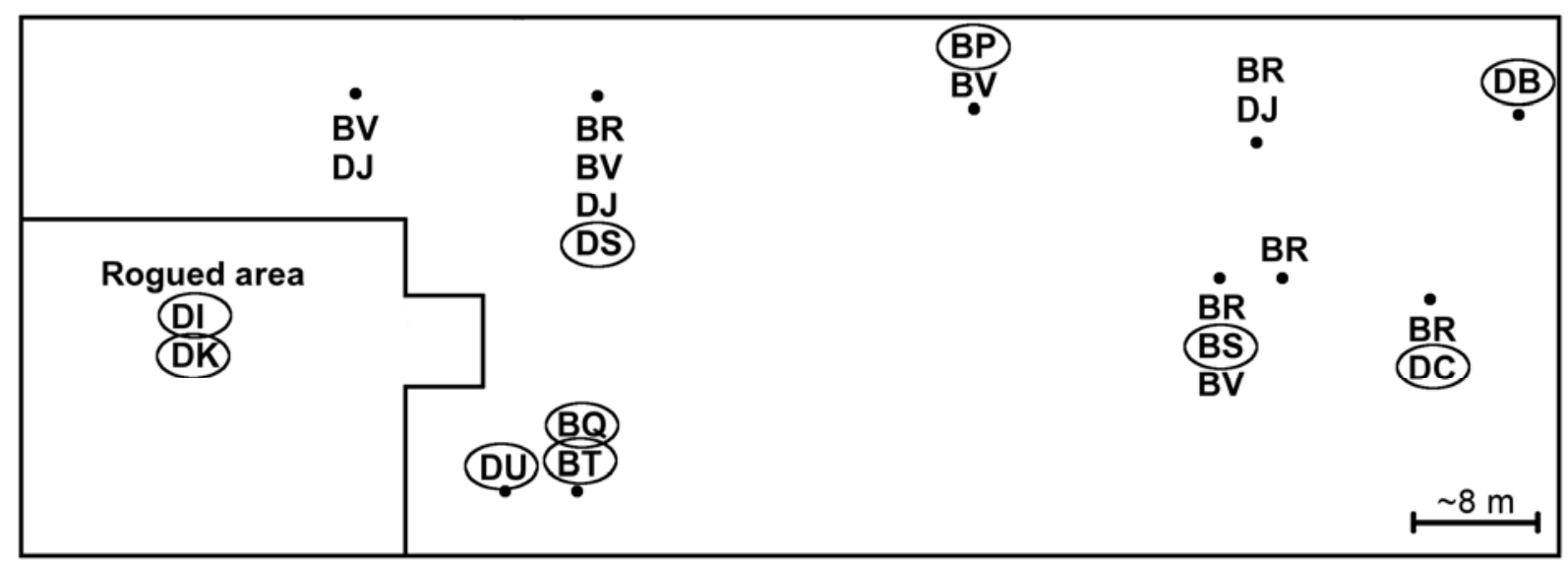

Fig. 2. Relative location of sampling points in a field located in western New York (site WNY-2) from which plants showing symptoms of Phytophthora blight were collected in June 2007. Each dot indicates a location where two to seven plants were sampled. Six plants were collected from the area designated by the irregular box in the lower left corner of the field, but exact locations are not known. Multilocus genotypes sampled from each location in the field are indicated by a two-letter code, and circled genotypes were found at a single location in this field. 
isolates of $P$. capsici were included as positive controls.

Amplification and analysis of microsatellite fragments. Microsatellite regions were amplified from $25 \mathrm{ng}$ of genomic DNA using microsatellite primers for loci Pcap1, Pcap3, Pcap4, Pcap5, and Pcap7, as described by Meitz et al. (32). Electropherograms were visualized in Peak Scanner (Applied Biosystems), and allele sizes at the five loci were manually scored. This technique was validated in our lab using DNA from $P$. capsici isolates characterized by Meitz et al. (32). New York isolates were assigned to multilocus genotypes (MLGs) based on alleles present at the five microsatellite loci, as well as mating type of each isolate. When the same MLG was detected in more than one isolate from the same plant, only one isolate per MLG per plant was used for the analysis, since we could not be sure that these isolates resulted from independent infections.

Statistical analysis. To estimate genotypic diversity, the normalized Shannon index $\left(D^{\prime}\right)$ was calculated for each site from which at least 10 isolates were sampled (30): $D^{\prime}=D / \ln N$, where $D=-\Sigma p_{i} \ln p_{i}$ (the Shannon index; where $p_{i}$ is the frequency of the $i$ th MLG) and $N$ is the number of isolates sampled from each site. A chi-square goodness-of-fit test was used to determine whether the ratio of A1 to A2 isolates differed significantly from $1: 1$ at sites from which at least 10 isolates were sampled (40). $P_{\text {sex }}(f)$, the probability that isolates from the same site with the same five-locus genotype (not including mating type) were the products of distinct sexual reproduction events, instead of resulting from clonal propagation, was calculated considering departures from HardyWeinberg equilibrium using GENCLONE version $2.0(2,3)$. $P_{\text {sex }}(f)$ was only calculated for sites with 10 or more isolates, and isolates with missing data at one or more loci were excluded from this analysis.

Arlequin version 3.11 (9) was used to calculate allele frequencies at each site, and to conduct all tests described below, using data only from the five microsatellite loci. Sites from which fewer than 10 isolates were sampled were excluded from analyses, with the exception of pairwise comparisons $\left(\mathrm{F}_{\mathrm{ST}}\right)$ between regions and hosts, analysis of molecular variance (AMOVA) partitioned by host, and allele frequencies. To test for differentiation between $P$. capsici populations sampled at different sites, from different regions of New York, or from different hosts, pairwise $F_{\text {ST }}$ values were estimated, and significance levels were tested with 1,023 permutations. An AMOVA was used to estimate the proportion of variation in the New York $P$. capsici population which resulted from differences among regions, among sites within regions, among individuals within sites, and among isolates sampled from different host plants. Significance was tested with 5,000 permutations (10). To estimate inbreeding or deviations from random mating, fixation indices $\left(\mathrm{F}_{\mathrm{IS}}\right)$ were calculated, and significance was tested with 5,040 permutations $(4,14)$. Because the significance test performed in Arlequin was one-sided, $P$ values for negative $F_{I S}$ values resulting from excess heterozygosity were determined by subtracting the estimated $P$ value from 1 . To test the hypothesis of random mating in each field, an exact test of Hardy-Weinberg equilibrium was performed on each locus at each site using a Markov chain with 1,000,000 steps and 100,000 dememorization steps (19). A locus was considered to be in Hardy-Weinberg

Table 2. Hardy-Weinberg equilibrium and inbreeding in populations of Phytophthora capsici sampled in 2006 to 2008 from 12 different sites in four regions of New York State ${ }^{\mathrm{a}}$

\begin{tabular}{|c|c|c|c|c|c|c|}
\hline \multirow[b]{2}{*}{ Region } & \multirow[b]{2}{*}{ Site } & \multirow[b]{2}{*}{$\mathbf{N}^{\mathbf{b}}$} & \multirow{2}{*}{$\begin{array}{c}\text { Number of } \\
\text { polymorphic } \\
\text { loci }\end{array}$} & \multirow[b]{2}{*}{$H_{W E}^{c}$} & \multicolumn{2}{|c|}{ Fixation index } \\
\hline & & & & & $\mathbf{F}_{\text {IS }}$ & $P^{\mathrm{d}}$ \\
\hline \multirow[t]{2}{*}{ WNY } & WNY-2 & 36 & 4 & 2 & 0.702 & 0.000 \\
\hline & WNY-3 & 12 & 5 & 1 & 0.662 & 0.000 \\
\hline $\mathrm{CNY}$ & CNY-2 & 13 & 4 & 3 & -0.193 & 0.091 \\
\hline \multirow[t]{3}{*}{$\mathrm{CD}$} & CD-1 & 13 & 5 & 1 & 0.384 & 0.001 \\
\hline & CD-2 & 16 & 2 & 1 & 0.464 & 0.007 \\
\hline & CD-4 & 23 & 5 & 3 & 0.363 & 0.000 \\
\hline \multirow[t]{5}{*}{ LI } & LI-1 & 11 & 5 & 1 & 0.450 & 0.000 \\
\hline & LI-9 & 11 & 5 & 3 & 0.480 & 0.007 \\
\hline & LI-10 & 12 & 4 & 1 & -0.247 & 0.089 \\
\hline & LI-11 & 12 & 5 & 1 & -0.007 & 0.431 \\
\hline & LI-12 & 44 & 5 & 0 & 0.330 & 0.000 \\
\hline
\end{tabular}

${ }^{a}$ Sites are grouped by region: $\mathrm{WNY}=$ western New York, $\mathrm{CNY}=$ central New York, CD = Capital District (near Albany, NY), and LI = Long Island. Data for sites from which fewer than 10 isolates were sampled are not shown.

${ }^{\mathrm{b}}$ Number of isolates sampled at each site. If a genotype was detected more than once in a single plant, only one representative isolate was included in the analysis.

${ }^{\mathrm{c}}$ Number of polymorphic loci in Hardy-Weinberg equilibrium (see Materials and Methods for description of Hardy-Weinberg analysis).

${ }^{\mathrm{d}} P$ values for $\mathrm{F}_{\mathrm{IS}}$ were calculated in Arlequin (9) using the number of different alleles to estimate distance. Significance was tested with 5,040 permutations. equilibrium if the observed heterozygosity did not differ significantly from that expected under Hardy-Weinberg equilibrium at $P=0.1$.

\section{RESULTS}

Isolation of $\boldsymbol{P}$. capsici and resistance to mefenoxam. In 2006, 2007, and 2008, we sampled 257 isolates of $P$. capsici from symptomatic summer squash, pumpkin, sweet pepper, hot pepper, tomato, winter squash, and eggplant. We detected mefenoxam-resistant isolates in all four sites in the Capital District, and in six of the 12 sites in Long Island (Table 1). In total, $66 \%$ of the isolates sampled in the Capital District were mefenoxam resistant, and $25 \%$ of the isolates sampled in Long Island were either intermediately or fully resistant to mefenoxam. In contrast, we did not detect any mefenoxam-resistant isolates in central New York or western New York.

Polymorphisms in mating type and structure within populations. At least one isolate of each mating type (A1 or A2) was found in 12 of the 22 sites. In the Capital District, A1:A2 ratios did not differ significantly from $1: 1$ at any of the three sites with at least 10 isolates; in Long Island, A1:A2 ratios did not differ significantly from 1:1 at three of five sites with at least 10 isolates. At the remaining two sites in Long Island with at least 10 isolates, all isolates were either A1 or A2. At the only central New York site with a sample size of at least 10, all isolates were A2. Both A1 and A2 isolates were found at the two western New York sites with at least 10 isolates sampled; at one site the ratio differed significantly from 1:1 (Table 1).

One or two alleles were amplified at each of the five microsatellite loci in all but 12 of the 257 isolates studied, and between five and 10 alleles were observed at each microsatellite locus. We interpreted the presence of one allele per locus as a homozygote, whereas two alleles indicated heterozygotes. Loci at which no alleles were amplified were treated as missing data, and isolates containing missing data were excluded from calculations of $P_{\text {sex }}(f)$ and the normalized Shannon index. All five loci were polymorphic in seven of the 11 sites from which at least 10 isolates were sampled (Table 2). At each of six sites in Long Island, we found one, two, or three private alleles each at a single site and nowhere else in the state. Three other alleles were found in multiple Long Island sites but nowhere else in the state. Only nine of the 42 alleles were observed in all four regions of New York. At no site were all of the polymorphic loci in HardyWeinberg equilibrium (Table 2). Populations from eight out of 11 sites from which 10 or more isolates were sampled had fixation indices $\left(\mathrm{F}_{\mathrm{IS}}\right)$ that were significantly different from zero $(P \leq 0.05)$, indicating deviations from random mating. The remaining three sites had negative $\mathrm{F}_{\mathrm{IS}}$ 
values, although none were significant at $P$ $\leq 0.05$ (Table 2).

We found 114 MLGs defined by alleles at five microsatellite loci among 257 isolates. Twelve of these MLGs included isolates of both $\mathrm{A} 1$ and $\mathrm{A} 2$ mating type (data not shown), for a total of 126 MLGs when mating type and microsatellite alleles were used together to define MLGs. Multiple MLGs were detected at all sites, even those at which only one mating type was found, except for LI-7 $(N=7)$ and two sites where only one isolate was sampled (WNY-1 and CNY-1). Nine MLGs were detected at two or three sites; five of these nine MLGs were detected in two regions. Only four MLGs were detected in more than one year. On 14 occasions, multiple isolations were made from the same fruit or plant, and only one MLG was isolated from eight of these samples. Two different MLGs (of the same mating type) were isolated from the same plant or the same fruit on five occasions, and five MLGs (all of the A2 mating type) were isolated from a single winter squash fruit at site CD-2. Normalized Shannon indices ranged from 0.26 to 1.00 (Table 1 ).

At site WNY-2, the relative location of each sampling point was known, and distances between sampling points ranged from approximately 4 to $85 \mathrm{~m}$. Because locus Pcap3 was monomorphic at this site, MLG determination at WNY-2 was based on mating type and alleles at only four microsatellite loci. Nevertheless, 13 MLGs were identified among 36 isolates. Ten MLGs were detected only at a single sampling point, although sometimes from multiple plants at that location. Three MLGs (BV, DJ, and BR) were found at three or more places in the field, not only at nearby sampling points, but also at opposite ends of the field. At two sampling points, two MLGs (BV and BS; BV and $\mathrm{BP})$ were isolated from distinct lesions on the same plant. These were the only plants from which multiple lesions were sampled at this site (Fig. 2).
Genetic differentiation among populations. All but one pairwise comparison between sites indicated significant differentiation $(P \leq 0.05)$, whether or not the sites were located in the same region of the state (Table 3). Pairwise comparisons between regions also showed significant differentiation between $P$. capsici populations in all four regions (Table 4). Results from AMOVA also showed significant levels of differentiation among regions and sites $(P<0.005)$. Across the state, nearly $24 \%$ of variation was attributed to differences among regions, while more than $16 \%$ was attributed to variation among sites within regions, and more than $20 \%$ was attributed to variation within each site.

Variation among hosts, within hosts, and within individuals were all significant $(P<$ $0.0001)$, but intrahost variation $(42 \%)$ was greater than interhost variation (14\%). Although pairwise comparisons showed significant differentiation between $P$. capsici populations from different hosts (data not shown), the number of isolates sampled from each host varied greatly, and fewer than five isolates were obtained from tomatoes and eggplants. In addition, a disproportionate number of the pumpkin isolates came from Long Island, making it difficult to separate the effects of differentiation by region from differentiation by host.

Table 4. Genetic differentiation of populations of Phytophthora capsici from four regions of New York sampled in 2006 to $2008^{a}$

\begin{tabular}{|c|c|c|c|c|}
\hline \multirow[b]{2}{*}{ Region } & \multicolumn{4}{|c|}{$\mathbf{F}_{\text {ST }}$ values $^{b}$} \\
\hline & WNY & CNY & CD & LI \\
\hline WNY & - & & & \\
\hline $\mathrm{CNY}$ & $0.316^{* *}$ & - & & \\
\hline CD & $0.395^{* *}$ & $0.244 * *$ & - & \\
\hline LI & $0.344 * *$ & $0.191 * *$ & $0.051 * *$ & - \\
\hline
\end{tabular}

Many MLGs were detected in more than one isolate per site, each from a different plant. Most MLGs (defined by alleles at five microsatellite loci only) were detected in eight or fewer isolates at the same site, but two MLGs were detected in nine and 11 isolates, respectively, at site WNY-2, and two other MLGs were detected in 15 and 20 isolates, respectively, at site LI-12 (data not shown). For each MLG detected in more than one isolate, we estimated $P_{\text {sex }}$ $(f)$, the probability that some members of this MLG could have arisen independently by sexual reproduction instead of through clonal propagation. $P_{\text {sex }}(f)$ was greater than 0.05 for 19 out of 25 MLGs detected in two or more isolates from sites where 10 or more isolates were sampled.

\section{DISCUSSION}

Resistance to mefenoxam. The prevalence of mefenoxam-resistant isolates in Long Island and the Capital District indicates that mefenoxam should no longer be used to manage Phytophthora blight in these regions unless it is known that $P$. capsici isolates in a specific field are still sensitive $(7,20,36)$. The detection of mefenoxam-resistant isolates at all sampling sites in the Capital District is significant because mefenoxam had previously been an important component of Phytophthora blight management on some vegetable

Table 3. Genetic differentiation of populations of Phytophthora capsici sampled at 11 different sites in four regions of New York State during the 2006 to 2008 growing seasons ${ }^{\mathrm{a}}$

\begin{tabular}{|c|c|c|c|c|c|c|c|c|c|c|}
\hline \multirow[b]{2}{*}{ Sites $^{c}$} & \multicolumn{10}{|c|}{$\mathbf{F}_{\text {ST }}$ values $^{b}$} \\
\hline & CD-1 & CD-2 & CD-4 & WNY-3 & WNY-2 & CNY-2 & LI-1 & LI-9 & LI-10 & LI-11 \\
\hline CD-1 (13) & 0 & & & & & & & & & \\
\hline CD-2 (16) & $0.261 * *$ & 0 & & & & & & & & \\
\hline CD-4 (23) & $0.086^{*}$ & $0.230 * *$ & 0 & & & & & & & \\
\hline WNY-3 (12) & $0.366^{* *}$ & $0.623 * *$ & $0.277 * *$ & 0 & & & & & & \\
\hline WNY-2 (36) & $0.555^{* *}$ & $0.699 * *$ & $0.410 * *$ & $0.083^{*}$ & 0 & & & & & \\
\hline CNY-2 (13) & $0.337 * *$ & $0.497 * *$ & $0.213 * *$ & $0.274 * *$ & $0.382 * *$ & 0 & & & & \\
\hline LI-1 (11) & 0.039 & $0.274 * *$ & $0.090^{*}$ & $0.269 * *$ & $0.493 * *$ & $0.251^{* *}$ & 0 & & & \\
\hline LI-9 (11) & $0.197 * *$ & $0.367 * *$ & $0.120^{*}$ & $0.503 * *$ & $0.609 * *$ & $0.338^{* *}$ & $0.156^{* *}$ & 0 & & \\
\hline LI-10 (12) & $0.197 * *$ & $0.386^{* *}$ & $0.203 * *$ & $0.459 * *$ & $0.601 * *$ & $0.360^{* *}$ & $0.126^{*}$ & $0.322 * *$ & 0 & \\
\hline LI-11 (12) & $0.262 * *$ & $0.461 * *$ & $0.262 * *$ & $0.377 * *$ & $0.545^{* *}$ & $0.317 * *$ & $0.145^{*}$ & $0.365^{* *}$ & $0.082 *$ & 0 \\
\hline LI-12 (44) & $0.135^{* *}$ & $0.329 * *$ & $0.213 * *$ & $0.427 * *$ & $0.570 * *$ & $0.365^{* *}$ & $0.125^{*}$ & $0.298 * *$ & $0.283 * *$ & $0.347 * *$ \\
\hline
\end{tabular}

a Sites with fewer than 10 isolates have been excluded from the analysis.

${ }^{\mathrm{b}} \mathrm{F}_{\mathrm{ST}}$ values were calculated in Arlequin (9) with distances between populations based on allele frequencies in each population. Values followed by $*$ and $* *$ are significantly different from zero at $P<0.05$ and $P<0.001$, respectively, using 1,023 permutations.

${ }^{c}$ Number of isolates found at each site follows the site name in parentheses. If a genotype was detected in more than one isolate from the same plant, only one representative isolate was included in the analysis. 
crops in this region. The fact that no resistant isolates were found in central or western New York is consistent with the hypothesis that mefenoxam resistance, if present, is not as widespread in these regions as it is in the Capital District and Long Island. However, failure to find mefenoxam-resistant isolates in central and western New York may also be related to the comparatively small numbers of isolates sampled from these regions. Because of differences in sample sizes, we cannot speculate on whether the different frequencies of mefenoxam-resistant isolates in the Capital District and Long Island support the hypothesis of low levels of gene flow between these two regions. Since mefenoxam resistance appears to be conferred by a single, incompletely dominant gene in $P$. capsici (20), multiple independent mutations followed by selection for resistant individuals may be the source of mefenoxam-resistance in the Capital District and Long Island. In that case, frequency of mefenoxam resistance would be unrelated to gene flow between regions. While mefenoxam may still be a useful management tool on some farms in western and central New York where resistance has not been detected, it should still be used in rotation with fungicides with different modes of action in order to slow the development of resistance in $P$. capsici populations.

Within population structure: Reproductive biology of $P$. capsici. The importance of both sexual and asexual reproduction in temperate populations of $P$. capsici is well-established $(20,37)$, and our results are consistent with mixed reproductive modes for $P$. capsici populations in New York. Annual sexual reproduction is expected because oospores are the overwintering form of inoculum, and while the frequent sampling of both A1 and A2 isolates of P. capsici from the same New York site does not prove that sexual reproduction is occurring, it does mean that sexual reproduction is possible (12). Our failure to reject a $1: 1$ ratio of $\mathrm{A} 1$ to $\mathrm{A} 2$ mating types at some sites is also consistent with the hypothesis that these populations are randomly mating, as are the estimates of high genotypic diversity at some sites $(12,24,27,30,34)$. It is unknown whether populations in which only one mating type were detected are actually clonal, and therefore will not persist from one season to another, or whether our detection of a single mating type is due to the small sample sizes.

Plant pathogens which reproduce both sexually and asexually are not expected to exclusively display characteristics of either random mating or complete clonality (34), so the fact that we found deviations from expectations under random mating in New York populations of $P$. capsici is consistent with the biology of the pathogen. After sexual oospores germinate to initiate an epidemic, sporangia and zoospores are produced through clonal propagation, allowing for the extensive spread of $P$. capsici throughout a field under conducive weather conditions, with the most fit genotypes increasing in frequency throughout the growing season (20). Departures from 1:1 mating type ratios, polymorphic loci not in Hardy-Weinberg equilibrium, low genotypic diversity at some sites even if large numbers of isolates were sampled, and high $\mathrm{F}_{\mathrm{IS}}$ values observed in New York fields are all consistent with the mixed reproductive mode of $P$. capsici $(4,14,34)$.

A previous study found that a single $P$. capsici clone was represented by an increasing proportion of sampled isolates over the course of the growing season (25). Based on this observation, we expected New York populations sampled later in the growing season to show more characteristics of clonality. For this reason, it is interesting that more unique MLGs (19 versus 13) were detected at site CD-4 $(N=23)$ than at site WNY-2 $(N=36)$, even though the former was sampled later in the season. Perhaps the diversity and structure of the $P$. capsici population at site CD-4 (or in the Capital District) differs from $P$. capsici populations in other parts of New York. Regional differences in population structure were reported in a study of the Mexican population of $P$. infestans, where isolates found in the northwestern part of the country represented only a few genotypes, while almost all isolates from central Mexico had unique genotypes (15). It should also be noted that site CD-4 is located along the Mohawk River, and the site flooded in the spring of 2007. P. capsici has frequently been found in surface water $(13,38,43)$, and the high diversity observed at this site could be a result of inoculum from multiple farms upstream being deposited in the field during this flood event. Alternatively, different environmental conditions and host availability in these independent fields could have led to the epidemic in each field being initiated on a different date.

Genetic differentiation and gene flow within New York. This study suggests that $P$. capsici in New York is not a single population, but rather is composed of subpopulations with highly restricted gene flow among them. Pairwise $F_{S T}$ values between both sites and regions, as well as the partitioning of more than $40 \%$ of total variation either between regions or between sites, support this conclusion. This is expected for a soilborne organism like $P$. capsici which is not aerially dispersed (18). $\mathrm{F}_{\mathrm{ST}}$ values less than 0.05 are often considered to be consistent with low, but still potentially important, levels of genetic differentiation between populations, while values between 0.15 and 0.25 suggest moderate differentiation, and values exceeding 0.25 indicate high levels of differentiation $(5,45)$. Nearly all of the pairwise $\mathrm{F}_{\mathrm{ST}}$ values calculated between sites and regions in this study were greater than 0.05 , and often substantially so (Tables 3 and 4), suggesting low or very low levels of gene flow between sites and regions. Alternatively, higher levels of gene flow could be masked by annual bottlenecks that occur due to the failure of asexual propagules to survive the winter. This hypothesis has less support because loss of genotypic diversity from one year to another has not been observed in populations of $P$. capsici in Michigan (25).

Furthermore, only nine out of 126 MLGs were found at two different sites. While these nine MLGs may be examples of rare migration of individuals (genotype flow) between sites and regions, it is more likely that they arose independently by sexual reproduction, but appear to have the same genotype because MLGs are determined by alleles at only five microsatellite loci. We do not expect that an MLG could persist asexually beyond a single growing season in New York, and the four MLGs detected in both 2007 and 2008 are probably examples of MLGs that arose independently by sexual reproduction. $P_{\text {sex }}(f)$ estimates the probability that an MLG sampled more than once arose independently in a population multiple times through sexual reproduction instead of arising once and being propagated through asexual reproduction. Because many $P_{\text {sex }}$ (f) values within sites were high, it is also possible that the same MLGs arose independently in distant fields through sexual reproduction, instead of being a single clone which spread across the state. Furthermore, the fact that some MLGs differed only by mating type also suggests that they arose independently via sexual reproduction, because it is unlikely that one mating type can mutate to the other (23). Additional polymorphic markers would increase the resolution for genotyping genetically distinct individuals, and with more markers, it is likely that we could detect greater diversity in populations of $P$. capsici than has been described in this study. In spite of this, five microsatellite markers were sufficient to show evidence for a diverse, subdivided population with restricted gene flow.

High levels of differentiation between populations at different sites, even within the same region, are likely to have arisen by restricted gene flow combined with founder effects, selection, or bottlenecks. Restricted gene flow among fields would promote the genetic differences between fields by preventing the homogenization of populations in different fields. Once populations are established, divergence and differentiation will occur by mutation, drift, and selection (14) in the absence of gene flow. Differentiation could arise randomly in the first place depending on the genotypes and diversity of the founding individuals. Alternatively, fields may have been founded by highly diverse popula- 
tions, followed by the loss of genotypes due to reductions of population size over the winter. Such bottlenecks could cause differentiation due to random loss of different genotypes in each field (i.e., genetic drift). The bottleneck hypothesis has less support than founder effects based on previous observations of $P$. capsici populations (25), as discussed above. The use of microsatellite markers assumes that all alleles of the same size are identical by descent. If alleles of the same size arose independently in more than one field, it would be impossible to distinguish this from gene flow between fields.

Site WNY-2. In cold climates, sexual oospores must be produced in order for $P$. capsici to survive from one growing season to another, and are therefore expected to be the primary inoculum at the beginning of each growing season $(6,27)$. A study of the mapped sampling of $P$. infestans isolates from a single field in Sweden almost always detected each MLG at a single location in the field, and this was interpreted as evidence for oospores as the primary inoculum in the epidemic (44). The fact that most MLGs were only found at one sampling point at site WNY-2 is consistent with oospores as the primary inoculum in this field. The detection of three MLGs at multiple points within the field is consistent with the established importance of asexual reproduction in the life cycle of $P$. capsici and the spread of sporangia and zoospores through a field during rain events, primarily via surface run-off and splashing from infested soil or infected plant tissue $(18,20,37)$. The 2.18 and $3.68 \mathrm{~cm}$ of rain that fell at site WNY-2 9 and 11 days prior to sampling, respectively, likely presented such an opportunity for asexual propagules to be spread through the field.

Comparison to other $\boldsymbol{P}$. capsici populations and implications for management. The low levels of gene flow among sites and the varying levels of genotypic diversity detected at each site in New York are consistent with previous reports in Michigan populations of $P$. capsici $(26,27)$. Similarly, in a study of $P$. capsici from irrigation ponds in Georgia using microsatellites, no MLG was detected in more than one pond (43). In contrast, studies on small numbers of $P$. capsici isolates from Illinois (22), or northwestern Spain (41), found no correlation between random amplified polymorphic DNA (RAPD) groups and sampling location. High levels of genotypic diversity were detected in South African $P$. capsici populations, but the same MLG was detected over multiple regions and years (32), while in coastal Peru, the $P$. capsici population appears to be clonal (21). Thus, populations of P. capsici in New York have similar structures to some but not all previously surveyed $P$. capsici populations. Our findings are also consistent with known dispersal mechanisms for
P. capsici, which include movement of surface water, soil, and plant material, but not aerial dispersal, and with the important role that both sexual and asexual reproduction play in the life cycle of $P$. capsici in cold climates $(18,20)$.

As expected based on the biology of $P$. capsici, this study suggests that human activity is the most likely explanation for long-distance spread of $P$. capsici in New York via infected plants and infested soil. Our finding that even fields in the same county have highly differentiated populations emphasizes the degree to which gene flow is restricted among populations. Because some farms in New York are infested with $P$. capsici, while others nearby are not, it is crucial that growers take steps to avoid moving $P$. capsici into uninfested fields by not moving culled plants or potentially infested soil. If mefenoxam resistance is not yet present in central and western New York, then preventing the introduction of $P$. capsici inoculum from other parts of the state and rotating fungicides with different modes of action could help to prolong the efficacy of this fungicide for managing Phytophthora blight.

This study does not address the potential role that movement of surface water may play in dispersal of $P$. capsici between New York fields located in the same watershed. Because of the frequent recovery of $P$. capsici from surface water in previous studies, watersheds may have an impact on gene flow between fields, and further work is warranted in this area. In the meantime, steps should be taken to prevent the contamination of irrigation sources by $P$. capsici, and only noninfested water should be used to irrigate susceptible crops. A recent study indicated that some algaecides may kill or inhibit the movement and infectivity of $P$. capsici zoospores in water (17), and further study is needed to determine how irrigation sources could be treated to limit the dissemination of $P$. capsici.

Another study reported the development of 31 microsatellite markers that were polymorphic in $P$. capsici isolates sampled from irrigation ponds in Georgia (43). If some of these markers are also polymorphic in New York populations, then they could be used to further characterize the New York population. For example, our study does not address temporal variation of $P$. capsici populations in the state, and knowledge of the similarity between populations from the same field in different years could provide additional information about how $P$. capsici populations change over time. Additional markers could also be useful in studying the distribution of clonal lineages of $P$. capsici within New York watersheds.

\section{ACKNOWLEDGMENTS}

This study was funded in part by a grant from the New York State Department of Agriculture and Markets. The authors thank New York State vegetable growers and Cornell Cooperative Extension educators for their assistance in obtaining symptomatic plants; H. W. Lange, A. McKinney, K. L. Myers, P. Duque, and B. Fry for technical assistance; undergraduate researchers from Keuka College R. Bailey, R. Lee, and C. Peeck; and the Hobart and William Smith Colleges Office of the Provost for support of S. Tandle.

\section{LITERATURE CITED}

1. Anderson, J. B., and Kohn, L. M. 1995. Clonality in soilborne, plant-pathogenic fungi. Annu. Rev. Phytopathol. 33:369-391.

2. Arnaud-Haond, S., Alberto, F., Teixeira, S. Procaccini, G., Serrao, E. A., and Duarte, C. M. 2005. Assessing genetic diversity in clonal organisms: Low diversity or low resolution? Combining power and cost efficiency in selecting markers. J. Hered. 96:434-440.

3. Arnaud-Haond, S., and Belkhir, K. 2007. GENCLONE: A computer program to analyse genotypic data, test for clonality and describe spatial clonal organization. Mol. Ecol. Notes 7:15-17.

4. Balloux, F., Lehmann, L., and de Meeus, T. 2003. The population genetics of clonal and partially clonal diploids. Genetics 164:16351644.

5. Balloux, F., and Lugon-Moulin, N. 2002. The estimation of population differentiation with microsatellite markers. Mol. Ecol. 11:155-165.

6. Bowers, J. H., Papavizas, G. C., and Johnston, S. A. 1990. Effect of soil temperature and soilwater matric potential on the survival of Phy tophthora capsici in natural soil. Plant Dis. 74:771-777.

7. Café-Filho, A. C., and Ristaino, J. B. 2008. Fitness of isolates of Phytophthora capsici resistant to mefenoxam from squash and pepper fields in North Carolina. Plant Dis. 92:14391443.

8. Erwin, D. C., and Ribeiro, O. K. 1996. Phytophthora Diseases Worldwide. American Phytopathological Society, St. Paul, MN.

9. Excoffier, L., Laval, G., and Schneider, S. 2005. Arlequin ver. 3.0: An integrated software package for population genetics data analysis. Evol. Bioinform. Online 1:47-50.

10. Excoffier, L., Smouse, P. E., and Quattro, J. M. 1992. Analysis of molecular variance inferred from metric distances among DNA haplotypes Application to human mitochondrial-DNA restriction data. Genetics 131:479-491.

11. French-Monar, R. D., Jones, J. B., and Roberts, P. D. 2006. Characterization of Phytophthora capsici associated with roots of weeds on Florida vegetable farms. Plant Dis. 90:345-350.

12. Fry, W. E., Goodwin, S. B., Matuszak, J. M., Spielman, L. J., Milgroom, M. G., and Drenth, A. 1992. Population genetics and intercontinental migrations of Phytophthora infestans. Annu. Rev. Phytopathol. 30:107-129.

13. Gevens, A. J., Donahoo, R. S., Lamour, K. H., and Hausbeck, M. K. 2007. Characterization of Phytophthora capsici from Michigan surface irrigation water. Phytopathology 97:421428.

14. Goodwin, S. B. 1997. The population genetics of Phytophthora. Phytopathology 87:462-473.

15. Goodwin, S. B., Spielman, L. J., Matuszak, J. M., Bergeron, S. N., and Fry, W. E. 1992. Clonal diversity and genetic differentiation of Phytophthora infestans populations in northern and central Mexico. Phytopathology 82:955961.

16. Goodwin, S. B., Sujkowski, L. S., and Fry, W. E. 1996. Widespread distribution and probable origin of resistance to metalaxyl in clonal genotypes of Phytophthora infestans in the United States and western Canada. Phytopathology 86:793-800

17. Granke, L. L., and Hausbeck, M. K. 2010. Effects of temperature, concentration, age, and algaecides on Phytophthora capsici zoospore 
infectivity. Plant Dis. 94:54-60.

18. Granke, L. L., Windstam, S. T., Hoch, H. C., Smart, C. D., and Hausbeck, M. K. 2009. Dispersal and movement mechanisms of Phytophthora capsici sporangia. Phytopathology 99:1258-1264

19. Guo, S. W., and Thompson, E. A. 1992. Performing the exact test of Hardy-Weinberg proportion for multiple alleles. Biometrics 48:361-372.

20. Hausbeck, M. K., and Lamour, K. H. 2004. Phytophthora capsici on vegetable crops: Research progress and management challenges. Plant Dis. 88:1292-1303.

21. Hurtado-Gonzáles, O., Aragon-Caballero, L., Apaza-Tapia, W., Donahoo, R., and Lamour, K. 2008. Survival and spread of Phytophthora capsici in coastal Peru. Phytopathology 98:688-694.

22. Islam, S. Z., Babadoost, M., Lambert, K. N., Ndeme, A., and Fouly, H. M. 2005. Characterization of Phytophthora capsici isolates from processing pumpkin in Illinois. Plant Dis. 89:191-197.

23. Judelson, H. S., Spielman, L. J., and Shattock, R. C. 1995. Genetic mapping and nonMendelian segregation of mating type loci in the oomycete, Phytophthora infestans. Genetics 141:503-512.

24. Lamour, K. H., and Hausbeck, M. K. 2000. Mefenoxam insensitivity and the sexual stage of Phytophthora capsici in Michigan cucurbit fields. Phytopathology 90:396-400.

25. Lamour, K. H., and Hausbeck, M. K. 2001. The dynamics of mefenoxam insensitivity in a recombining population of Phytophthora capsici characterized with amplified fragment length polymorphism markers. Phytopathology 91:553-557.

26. Lamour, K. H., and Hausbeck, M. K. 2002. The spatiotemporal genetic structure of Phytophthora capsici in Michigan and implications for disease management. Phytopathology 92:681-684.
27. Lamour, K. H., and Hausbeck, M. K. 2003. Effect of crop rotation on the survival of Phytophthora capsici in Michigan. Plant Dis. 87:841-845.

28. Lee, T. Y., Mizubuti, E., and Fry, W. E. 1999. Genetics of metalaxyl resistance in Phytophthora infestans. Fungal Genet. Biol. 26:118-130.

29. Leonian, L. H. 1922. Stem and fruit blight of peppers caused by Phytophthora capsici sp. nov. Phytopathology 12:401-408.

30. Liu, Y. C., Cortesi, P., Double, M. L., MacDonald, W. L., and Milgroom, M. G. 1996. Diversity and multilocus genetic structure in populations of Cryphonectria parasitica. Phytopathology 86:1344-1351.

31. McDermott, J. M., and McDonald, B. A. 1993. Gene flow in plant pathosystems. Annu. Rev. Phytopathol. 31:353-373.

32. Meitz, J. C., Line, C. C., Thompson, A., Langenhoven, S., and McLeod, A. Phytophthora capsici on vegetable hosts in South Africa: Distribution, host range and genetic diversity. Australas. Plant Pathol. 39:431-439.

33. Milgroom, M. G. 1995. Analysis of population structure in fungal plant pathogens. Pages 213229 in: Disease Analysis Through Genetics and Biotechnology. J. F. Leslie and R. A. Frederiksen, eds. Iowa State University, Ames, IA.

34. Milgroom, M. G. 1996. Recombination and the multilocus structure of fungal populations. Annu. Rev. Phytopathol. 34:457-477.

35. Papavizas, G. C., Bowers, J. H., and Johnston, S. A. 1981. Selective isolation of Phytophthora capsici from soils. Phytopathology 71:129.

36. Parra, G., and Ristaino, J. B. 2001. Resistance to mefenoxam and metalaxyl among field isolates of Phytophthora capsici causing Phytophthora blight of bell pepper. Plant Dis. 85:1069-1075.

37. Ristaino, J. B., and Johnston, S. A. 1999. Ecologically based approaches to management of Phytophthora blight on bell pepper. Plant
Dis. 83:1080-1089.

38. Roberts, P. D., Urs, R. R., French-Monar, R D., Hoffine, M. S., Seijo, T. E., and McGovern, R. J. 2005. Survival and recovery of Phytophthora capsici and oomycetes in tailwater and soil from vegetable fields in Florida. Ann. Appl. Biol. 146:351.

39. Schmitthenner, A. F., and Bhat, R. G. 1994 Useful methods for studying Phytophthora in the laboratory. Ohio Agricultural Research and Development Center, The Ohio State University, Wooster.

40. Sheskin, D. J. 1996. Handbook of Parametric and Nonparametric Statistical Procedures. CRC Press, Boca Raton, FL.

41. Silvar, C., Merino, F., and Diaz, J. 2006. Diversity of Phytophthora capsici in northwest Spain: Analysis of virulence, metalaxyl response, and molecular characterization. Plant Dis. 90:1135-1142.

42. Tooley, P. W., Fry, W. E., and Gonzalez, M. J. V. 1985. Isozyme characterization of sexual and asexual Phytophthora infestans populations. J. Hered. 76:431-435

43. Wang, Z. Y., Langston, D. B., Csinos, A. S., Gitaitis, R. D., Walcott, R. R., and Ji, P. S. 2009. Development of an improved isolation approach and simple sequence repeat markers o characterize Phytophthora capsici populations in irrigation ponds in southern Georgia Appl. Environ. Microbiol. 75:5467-5473.

44. Widmark, A. K., Andersson, B., CasselLundhagen, A., Sandstrom, M., and Yuen, J. E. 2007. Phytophthora infestans in a single field in southwest Sweden early in spring: Symptoms, spatial distribution and genotypic variation. Plant Pathol. 56:573-579.

45. Wright, S. 1978. Evolution and the Genetics of Populations. University of Chicago Press, Chicago.

46. Zhang, N., McCarthy, M. L., and Smart, C. D. 2008. A macroarray system for the detection of fungal and oomycete pathogens of solanaceous crops. Plant Dis. 92:953-960. 